\title{
Shear Lag Analysis due to Flexure of Prismatic Beams with Arbitrary Cross-Sections by FEM
}

\author{
Dang-Bao $\operatorname{Tran}^{1,2^{*}}$, Jaroslav Navrátil \\ ${ }^{1}$ Department of Structures, Faculty of Civil Engineering, VSB-Technical University of Ostrava, Ludvíka Podéště 1875/17, Ostrava, 708 \\ 00, Czech Republic \\ 2 Department of Civil Engineering, Faculty of Architecture, Thu Dau Mot University, Tran Van On 06, Thu Dau Mot City, Binh Duong \\ Province, 750 00, Vietnam \\ * Corresponding author, e-mail: dang.bao.tran@vsb.cz
}

Received: 11 August 2021, Accepted: 12 November 2021, Published online: 18 November 2021

\begin{abstract}
This paper presents the use of a finite element method (FEM) to analyze the shear lag effect due to the flexure of beams with an arbitrary cross-section and homogeneous elastic material. Beams are constrained by the most common types of supports, such as fixed, pinned, and roller. The transverse, concentrated, or distributed loads act on the beams through the shear center of the cross-section. The presented FEM transforms the 3D analysis of the shear lag phenomenon into separated 2D cross-sectional and 1D beam modeling. The characteristics of the cross-section are firstly derived from 2D FEM, which uses a 9-node isoparametric element. Then, a 1D FEM, which uses a linear isoparametric element, is developed to compute the deflection, rotation angle, bending warping parameter, and stress resultants. Finally, the stress field is obtained from the local analysis on the 2D-cross section. A MATLAB program is executed to validate the numerical method. The validation examples have proven the efficiency and reliability of the numerical method for analyzing shear lag flexure, which is a common problem in structural design.
\end{abstract}

Keywords

shear lag, flexure, warping, numerical method, finite element method, thin-walled beam

\section{Introduction}

In the engineering beam theory, the cross-sections are assumed to remain plane after flexure deformation, and therefore, the normal stress in the longitudinal direction is proportional to the distance from the neutral axis. However, with complex cross-sections such as thin-walled beam, double $\mathrm{T}$ beam, where the influence of warping is significant, the above theory is no longer reasonable. In this case, the normal stress is nonuniformly distributed over the width of the section. This phenomenon is called shear lag [1]. Various design codes and standards, such as AASHTO LRFD Bridge Design Specifications [2], Eurocode 2 [3], and Eurocode 3 [4], use the concept of effective flange width to consider the shear lag phenomenon. However, factors affecting shear lag, such as boundary conditions and loading type, have not been considered in these standards.

Many authors have researched the shear lag phenomenon. Reissner [5] established a displacement field along the axis of the beam, taking into account the effect of shear lag, which is expressed by a parabolic function, and used the principle of minimum potential energy to obtain the flange stress at the cross-section. Moffatt and Dowling [6] and Tenchev [7] investigated the parameters affecting shear lag using FEM. Chang and Zheng [8] compared the experiment results in cantilever box beam with those analyzed the shear lag and negative shear lag effects using finite-element technique and variation principle. To compare with the experimental results, Luo et al. $[9,10]$ established FEM by adding to each node of element two parameters, derivative of vertical displacement and maximum rotation angle caused by shear deformation. To improve Luo et al. $[9,10]$ numerical method, Zhou [11] enriched one degree of freedom, the derivative of maximum rotation angle caused by shear deformation, to each node. Luo et al. [12] derived the element stiffness matrix and force vector from the assumption of many axial displacement fields of box girders with varying depths. Chang [13] derived an analytical method from $[5,8]$ to calculate the shear lag of simply supported prestressed concrete. Lee et al. [14] utilized the FEM to 
explain the nature of negative shear slag. Luo et al. [15] analyzed shear lag in box girder under the combination of bending and axial forces. Lin and Zhao [16] obtained the longitudinal displacement in the flange of the box girders by the superposition of the infinite number of second or third-order binominal with unknown quantities. Zhou [17] proposed a new FEM to analyze the shear lag in prestressed concrete box girders. Qin et al. [18] postulated an analytical method to investigate the shear lag problem of a T-section beam by solving a system of Hamilton dual equations. The above studies presuppose that a spanwise displacement is a polynomial function that considers the warping of flanges.

Some of the scholars, Zhang [19], Zhang and Lin [20] and Prokić [21], proposed that the new axial displacement includes a warping function improved on the thin-walled beam theory of Vlasov [22]. El Fatmi [23, 24] derived the nonuniform shear and torsional warping of an arbitrary homogeneous cross-section from the Saint Venant beam problem. Le Corvec and Filippou [25] defined the axial displacement due to warping by interpolation warping degrees of freedom number on the cross-section to establish FEM formulation for shear torsional warping in the elastic and elastoplastic analysis of beams. Ferradi et al. [26] obtained FEM that accurately captures normal stress due to restrained warping by reproducing cross-sectional warping as a linear combination of warping modes. Dikaros and Sapountzakis [27] proposed an advanced beam theory to analyze the composite beam with arbitrary cross-section using the Boundary Element Method (BEM). Lewiński and Czarnecki [28] constructed the new first-order warping function, which integrated with the theories of Vlasov [22], El Fatmi [23, 24], Kim and Kim [29], Librescu and Song [30], and Timoshenko [31, 32] to compose the theories of straight elastic bars

Some authors, Sa-nguanmanasak et al. [33], Yamaguchi et al. [34], developed the 3D model to examine the shear lag phenomenon. However, the solution using shell or solid elements is still not more flexible and computationally efficient than determining the stress on the cross-section by superimposition technique, 2D cross-section, and 1D beam element. BEM has quickly developed in recent years and has been considered as FEM's rival [35]. However, the world's leading structural analysis software companies [36] still use FEM primarily. The purpose of this paper is to establish a numerical method using FEM to solve the shear lag flexure problem of the prismatic beam with an arbitrary cross-section in homogeneous isotropic elastic material, based on theoretical formulas derived from Dikaros and Sapountzakis [27]. A 2D FEM based on the Galerkin approach is obtained from computing the warping function of the corresponding elliptical differential equations. The other kinematical variables of the beam are computed from the principle of virtual work by developing a 1D FEM.

The paper is organized as follows: Section 2 briefly introduces the theoretical formulas for analyzing the shear lag flexure problem. Section 3 describes FEM. Section 4 illustrates several numerical examples. Finally, we close our paper with some concluding remarks.

\section{A brief introduction of the theoretical formulas for analyzing shear lag due to flexure}

Let us consider a prismatic beam with arbitrary cross-section, constant along the length $L$ with a modulus of elasticity $E$, and shear modulus $G$. The longitudinal axis is the x-axis, and the cross-sections lie in the $y-z$ plane. The coordinate system is $S x y z$ through the shear center, $S$, of the cross-section. $C X Y Z$ is the parallel system with $S x y z$ through the center of gravity $C$. The multiply connected domain $\Omega$ is bounded by $\mathrm{n}$ curves, $\Gamma_{1}, \Gamma_{2}, \ldots, \Gamma_{n-1}, \Gamma_{n}$, as Fig. 1 . Tangent vector $\boldsymbol{t}$ with associate coordinate s and normal vector $\boldsymbol{n}$ set up the right-handed system.

The beam is exposed to the arbitrary distributed or concentrated loads, transverse loading $p_{z}(x)$ along the $z$-direction, bending moment $m_{Y}(x)$, and warping moment $M_{\varphi_{c Y}^{p}}(x)$ along with the $Y$-direction. The cross-section is assumed with no distortion.

The geometric constants of the beam are defined as [27]

$$
\begin{aligned}
& A=\int_{\Omega} d \Omega, \\
& I_{Y Y}=\int_{\Omega} Z^{2} d \Omega, \\
& I_{Z Z}=\int_{\Omega} Y^{2} d \Omega, \\
& I_{\varphi_{C Y}^{P} \varphi_{C Y}^{P}}=\int_{\Omega} \varphi_{C Y}^{P} \varphi_{C Y}^{P} d \Omega,
\end{aligned}
$$

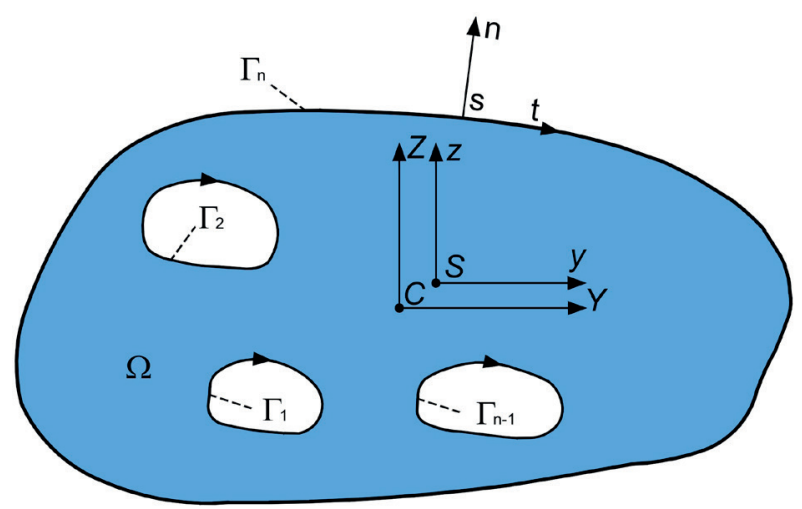

Fig. 1 Cross-section of a prismatic beam 
where $A$ is the area of cross-section, $I_{Y Y}, I_{Z Z}$ are the second moments of area with respect to $Z, Y$ - axis, respectively, $I_{\varphi_{c}^{p}, \varphi_{C r}^{p}}$ is the warping constant

$\varphi_{C Y}^{P}$ defines the primary shear warping function with respect to center of gravity $C$, which is obtained from

$\varphi_{C Y}^{P}=\phi_{C Y}^{P}-Z$,

where $\phi_{C Y}^{P}(y, z)$ is determined from the elliptical differential equations

$$
\begin{aligned}
& \nabla^{2} \phi_{C Y}^{P}=-\left(\frac{A_{Z}^{P}}{I_{Y Y}}\right) Z \text { in } \Omega, \\
& \frac{\partial \phi_{C Y}^{P}}{\partial y} n_{y}+\frac{\partial \phi_{C Y}^{P}}{\partial z} n_{z}=0 \text { on } \Gamma_{n},
\end{aligned}
$$

where $A_{Z}^{P}=k_{Z} A$ is defined as the primary shear area, $k_{Z}$ is the shear correction factor obtained from the definition given in [37]. It is worthy to note that the shear correction factor $k_{Z}$ in this study considers Poisson's ratio, which is neglected in [27].

In addition, the evaluated warping function $\phi_{C Y}^{P}$ from Eq. (3) contains an integration $c^{s}$, which can be obtained from Wagner and Gruttmann [38]

$c^{s}=-\frac{1}{A} \int_{\Omega} \phi_{C Y}^{P} d A$.

The displacement field is expressed as [27]

$$
\begin{aligned}
\bar{u}(x, y, z) & =\bar{u}^{P}(x, y, z)+\bar{u}^{S}(x, y, z) \\
& =\theta_{Y}(x) Z+\eta_{Y}(x) \varphi_{C Y}^{P}(y, z), \\
\bar{v}(x, y, z) & =0 \\
\bar{w}(x, y, z) & =w(x),
\end{aligned}
$$

where

$\bar{u}, \bar{v}, \bar{w}$ are the total displacements corresponding with the axis $x, y, z$.

$\bar{u}^{P}, \bar{u}^{S}(x, y, z)$ are the primary and secondary axial displacement, respectively

$w(x)$ deflection of the center of twist

$\theta_{Y}(x)$ is the angle of rotation due to flexure about the $Y$ axis $\eta_{Y}$ is the bending warping parameter.

The stress field obtained from the theory of elasticity as [27]

$$
\sigma_{x x}=E \varepsilon_{x x}=\underbrace{E \theta_{Y, x} Z}_{\sigma_{x x}^{P}}+\underbrace{E \eta_{Y, x}\left(\varphi_{C Y}^{P}\right)}_{\sigma_{x x}^{S}},
$$

$$
\begin{gathered}
\tau_{x y}=G \gamma_{x y}=\underbrace{G \gamma_{z}^{P}\left(Z_{, y}+\varphi_{C Y, y}^{P}\right)}_{\tau_{x y}^{P}}+\underbrace{G \gamma_{z}^{S}\left(\varphi_{C Y, y}^{P}\right)}_{\tau_{x y}^{S}}, \\
\tau_{x z}=G \gamma_{x z}=\underbrace{G \gamma_{z}^{P}\left(Z_{, z}+\varphi_{C Y, z}^{P}\right)}_{\tau_{x z}^{P}}+\underbrace{G \gamma_{z}^{S}\left(\varphi_{C Y, z}^{P}\right)}_{\tau_{x z}^{S}},
\end{gathered}
$$

where $\gamma_{Z}^{P}=w_{x}+\theta_{Y}, \gamma_{Z}^{S}=\eta_{Y}-w_{x}-\theta_{Y}$ are defined as the primary and secondary shear strain, respectively. It is emphasized that the stress component $\sigma_{z z}$ composed of $i$ ) the classic normal stress, $\sigma_{x x}^{P}$, determined from the engineering beam theory and ii) the warping normal stress, $\sigma_{x x}^{S}$, caused by warping of the cross-section, is the primary reason for the shear lag phenomenon.

The relation of the stress components, $\sigma_{x x}^{P}, \tau_{x y}^{P}, \tau_{x z}^{P}, \sigma_{x x}^{S}, \tau_{x y}^{S}$, $\tau_{x z}^{S}$, can be expressed by the equilibrium equation as [27]

$\frac{\partial \sigma_{x x}^{P}}{\partial x}+\frac{\partial \tau_{x y}^{P}}{\partial y}+\frac{\partial \tau_{x z}^{P}}{\partial z}=0$,

$\frac{\partial \sigma_{x x}^{S}}{\partial x}+\frac{\partial \tau_{x y}^{S}}{\partial y}+\frac{\partial \tau_{x z}^{S}}{\partial z}=0$.

The values $\tau_{x y}^{S}, \tau_{x z}^{S}$, which equilibrate with the variation of $\sigma_{x x}^{S}$ in Eq. (9), fail to fulfill the zero-traction condition on the lateral surface of the beam [27]. Dikaros and Sapountzakis [27] suggested a shear stress modification, $\tau_{x y}^{S}, \tau_{x z}^{S}$, by adding an additional warping function, $\varphi_{C Y}^{S}$. Therefore, Eq. (7) is transformed as

$$
\begin{gathered}
\tau_{x y}=G \gamma_{x y}=\underbrace{G \gamma_{z}^{P}\left(Z_{, y}+\varphi_{C Y, y}^{P}\right)}_{\tau_{x y}^{P}}+\underbrace{G \gamma_{z}^{S}\left(\Phi_{C Y, y}^{S}\right)}_{\tau_{x y}^{S}}, \\
\tau_{x z}=G \gamma_{x z}=\underbrace{G \gamma_{z}^{P}\left(Z_{, z}+\varphi_{C Y, z}^{P}\right)}_{\tau_{x z}^{P}}+\underbrace{G \gamma_{z}^{S}\left(\Phi_{C Y, z}^{S}\right)}_{\tau_{x z}^{S}},
\end{gathered}
$$

with $\Phi_{C Y}^{S}=\varphi_{C Y}^{P}+\varphi_{C Y}^{S}$,

where $\varphi_{C Y}^{S}$ is the secondary shear warping function with respect to the center of gravity $C$.

The value $\Phi_{C Y}^{S}$ is obtained from

$\Phi_{C Y}^{S}=-\left(\frac{A_{Z}^{S}}{I_{\varphi_{C Y}^{P} \varphi_{C Y}^{P}}^{P}}\right) \bar{\Phi}_{C Y}^{S}$,

where 


$$
\begin{aligned}
& A_{Z}^{S}=\frac{\left(I_{\varphi_{C Y}^{P} \varphi_{C Y}^{P}}\right)^{2}}{\int_{\Omega}\left[\left(\bar{\Phi}_{C Y, y}^{S}\right)^{2}+\left(\bar{\Phi}_{C Y, z}^{S}\right)^{2}\right] d \Omega}, \\
& \bar{\Phi}_{C Y}^{S}=\tilde{\Phi}_{C y}^{S}+Z C_{Y}, \\
& C_{Y}=\frac{I_{\varphi_{C Y}^{P} \varphi_{C Y}^{P}}}{A_{Z}^{P}},
\end{aligned}
$$

$\tilde{\Phi}_{C Y}^{S}$ is determined from the elliptical differential equations $\nabla^{2} \tilde{\Phi}_{C Y}^{S}=\left(\varphi_{C Y}^{P}\right)$ in $\Omega$

$\frac{\partial \tilde{\Phi}_{C Y}^{S}}{\partial y} n_{y}+\frac{\partial \tilde{\Phi}_{C Y}^{S}}{\partial z} n_{z}=0$ on $\Gamma_{n}$.

The bending moment, the warping moment, the primary shear force, the secondary shear force are denoted $M_{Y}, M_{\varphi_{c}^{\circ},} Q_{Z}^{P}, Q_{Z}^{S}$ obtained as [27]

$$
\begin{aligned}
& M_{Y}=\int_{\Omega} \sigma_{x x} Z d \Omega=E I_{Y Y} \theta_{Y, x}, \\
& M_{\varphi_{C Y}^{P}}=\int_{\Omega} \sigma_{x x} \varphi_{C Y}^{P} d \Omega=E I_{\varphi_{C Y}^{P} \varphi_{C Y}^{P}} \eta_{Y, x}, \\
& Q_{z}^{P}=\int_{\Omega}\left[\tau_{x y}\left(\phi_{C Y, y}^{P}\right)+\tau_{x z}\left(\phi_{C Y, z}^{P}\right)\right] d \Omega \\
& \quad=G \gamma_{z}^{P} \int_{\Omega}\left[\left(\phi_{C Y, y}\right)^{2}+\left(\phi_{C Y, z}\right)^{2}\right], \\
& Q_{z}^{S}=-\int_{\Omega}\left[\tau_{x y}\left(\Phi_{C Y, y}^{S}\right)+\tau_{x z}\left(\Phi_{C Y, z}^{S}\right)\right] d \Omega \\
& =-G \gamma_{z}^{S} \int_{\Omega}\left[\left(\Phi_{C Y, y}^{S}\right)^{2}+\left(\Phi_{C Y, z}^{S}\right)^{2}\right] d \Omega .
\end{aligned}
$$

\section{FEM procedures}

\subsection{Deflection $w(x)$, rotation angle $\theta_{Y}$, and bending}

\section{warping parameter $\eta_{Y}$}

The principle of virtual work ignoring volumetric forces is used to establish the stiffness matrix of the $1 \mathrm{D}$ beam element. Assume the beam element includes two end nodes, 1, 2, The symbol $\delta($.$) denotes the virtual quantities.$ The internal virtual work is

$W_{i}=\int_{V}\left(\sigma_{x x} \delta \varepsilon_{x x}+\tau_{x y} \delta \gamma_{x y}+\tau_{x z} \delta \gamma_{x z}\right) d V$,

where $V$ is the volume of a prismatic beam.

Substitution the Eq. (6), Eq. (10) and Eq. (15) to Eq. (16), the internal virtual work can be rewritten as

$$
\begin{aligned}
W_{i} & =E I_{Y Y} \int_{0}^{L} \delta\left(\theta_{Y, x}\right)\left(\theta_{Y, x}\right) d x+E I_{\varphi_{C Y}^{P} \varphi_{C Y}^{P}} \int_{0}^{L} \delta\left(\eta_{Y, x}\right) \eta_{Y, x} d x \\
& +G A_{Z}^{P} \int_{0}^{L} \delta\left(\gamma_{z}^{P}\right)\left(\gamma_{z}^{P}\right) d x+G A_{Z}^{S} \int_{0}^{L} \delta\left(\gamma_{z}^{S}\right)\left(\gamma_{z}^{S}\right) d x .
\end{aligned}
$$

The external virtual work is

$$
\begin{aligned}
& W_{e}=\underbrace{\int_{0}^{L}\left(p_{z}(x) \delta w_{x}+m_{Y}(x) \delta \theta_{Y}+m_{\varphi_{C Y}^{p}}(x) \delta \eta_{Y}\right) d x}_{\text {Span }} \\
& +\underbrace{\int_{\Omega}\left(t_{x} \delta \bar{u}+t_{y} \delta \bar{v}+t_{z} \delta \bar{w}\right) d \Omega}_{\text {end node, } 1}+\underbrace{\int_{\Omega}\left(t_{x} \delta \bar{u}+t_{y} \delta \bar{v}+t_{z} \delta \bar{w}\right) d \Omega}_{\text {end node, } 2},
\end{aligned}
$$

where $t_{x}, t_{y}, t_{z}$ are the components of traction vector applied on the lateral surface of the beam which is related to the end nodes - external loads as [27]

$$
\begin{aligned}
& \hat{p}_{z}(x)=\int_{\Omega} t_{z} d \Omega, \\
& \hat{m}_{Y}(x)=\int_{\Omega} t_{x} Z d \Omega, \\
& \hat{m}_{\varphi_{C Y}^{P}}(x)=\int_{\Omega} t_{x} \varphi_{C Y}^{P} d \Omega .
\end{aligned}
$$

Using the expression Eq. (5), Eq. (19), the Eq. (18) can be represented as

$$
\begin{aligned}
& W_{e}=\int_{0}^{L} p_{z}(x) \delta w_{x} d x+\int_{0}^{L} m_{Y}(x) \delta \theta_{Y} d x+\int_{0}^{L} m_{\varphi_{C Y}^{P}}(x) \delta \eta_{Y} d x \\
& +\sum_{i=1}^{2} \hat{p}_{z i} \delta w_{x i}+\sum_{i=1}^{2} \hat{m}_{Y i} \delta \theta_{Y i}+\sum_{i=1}^{2} \hat{m}_{\varphi_{C Y}^{P}} \delta \eta_{Y i} .
\end{aligned}
$$

To derive the element stiffness matrix, the variables $w_{x}$, $\theta_{Y}$, and $\eta_{Y}$ need to be interpolated within each element. $w_{x}$, $\theta_{Y}$, and $\eta_{Y}$ are independent variables. As a result, any kind of $H^{0}$ shape function can be used for the present beam. We use 1D linear isoparametric shape function for both variables. That is,

$$
\begin{aligned}
& w_{x}=\left[\begin{array}{ll}
N_{1}(\xi) & N_{2}(\xi)
\end{array}\right]\left\{\begin{array}{l}
w_{x 1} \\
w_{x 2}
\end{array}\right\}, \\
& \theta_{Y}=\left[\begin{array}{ll}
N_{1}(\xi) & N_{2}(\xi)
\end{array}\right]\left\{\begin{array}{l}
\theta_{Y 1} \\
\theta_{Y 2}
\end{array}\right\}, \\
& \eta_{Y}=\left[\begin{array}{ll}
N_{1}(\xi) & N_{2}(\xi)
\end{array}\right]\left\{\begin{array}{l}
\eta_{Y 1} \\
\eta_{Y 2}
\end{array}\right\},
\end{aligned}
$$

where $w_{x 1}, w_{x 2}, \theta_{Y 1}, \theta_{Y 2}, \eta_{Y 1}, \eta_{Y 2}$ are the nodal displacements, rotation angle, bending warping parameter at the beam end nodes (1) and (2), respectively

$$
N_{1}=\frac{1}{2}(1-\xi), N_{2}=\frac{1}{2}(1+\xi)
$$

The corresponding element nodal degrees of freedom is $\boldsymbol{d}=\left\{w_{x 1}, \theta_{Y 1}, \eta_{\mathrm{Y} 1}, w_{x 2}, \theta_{Y 2}, \eta_{\mathrm{Y} 2}\right\}^{T}$. 
Substituting Eq. (21), Eq. (22) to Eq. (17) and Eq. (20) leads to the element stiffness matrix and element force vector as

$$
\begin{aligned}
& \boldsymbol{K}^{e}=\boldsymbol{K}_{1}^{e}+\boldsymbol{K}_{2}^{e}+\boldsymbol{K}_{3}^{e}+\boldsymbol{K}_{4}^{e}, \\
& \boldsymbol{F}^{e}=\boldsymbol{F}_{1}^{2}+\boldsymbol{F}_{2}^{e}+\boldsymbol{F}_{3}^{e}+\sum_{i=1}^{2} \boldsymbol{F}_{i\left(p_{z}\right)}^{e}+\sum_{i=1}^{2} \boldsymbol{F}_{i\left(m_{Y}\right)}^{e}+\sum_{i=1}^{2} \boldsymbol{F}_{i\left(m_{\left.\phi_{C Y}\right)}^{e},\right.}^{e}
\end{aligned}
$$

where

$$
\begin{aligned}
\boldsymbol{K}_{1}^{e} & =E I_{Y Y} \int_{-1}^{1} \boldsymbol{B}_{1}^{T} \boldsymbol{B}_{1} J d \xi \\
& =E I_{Y Y} \sum_{i} w_{i} \boldsymbol{B}_{1}^{T}\left(\xi_{i}\right) \boldsymbol{B}_{1}\left(\xi_{i}\right) J, \\
\boldsymbol{K}_{2}^{e} & =E I_{\varphi_{C Y}^{p} \varphi_{C Y}^{p}} \int_{-1}^{1} \boldsymbol{B}_{2}^{T} \boldsymbol{B}_{2} J d \xi \\
& =E I_{\varphi_{C Y}^{p} \varphi_{C Y}^{p}}^{p} \sum_{i} w_{i} \boldsymbol{B}_{2}^{T}\left(\xi_{i}\right) \boldsymbol{B}_{2}\left(\xi_{i}\right) J, \\
\boldsymbol{K}_{3}^{e} & =G A_{Z}^{P} \int_{-1}^{1} \boldsymbol{B}_{3}^{T} \boldsymbol{B}_{3} J d \xi=G A_{Z}^{P} \sum_{i} w_{i} \boldsymbol{B}_{3}^{T}\left(\xi_{i}\right) \boldsymbol{B}_{3}\left(\xi_{i}\right) J, \\
\boldsymbol{K}_{4}^{e} & =G A_{Z}^{S} \int_{-1}^{1} \boldsymbol{B}_{4}^{T} \boldsymbol{B}_{4} J d \xi=G A_{Z}^{S} \sum_{i} w_{i} \boldsymbol{B}_{4}^{T}\left(\xi_{i}\right) \boldsymbol{B}_{4}\left(\xi_{i}\right) J, \\
\boldsymbol{F}_{1}^{e} & =\int_{-1}^{1} p_{z} \boldsymbol{B}_{5}^{T} J d \xi=\sum_{i} w_{i} \boldsymbol{B}_{5}^{T}\left(\xi_{i}\right) p_{z} J, \\
\boldsymbol{F}_{2}^{e} & =\int_{-1}^{1} m_{Y} \boldsymbol{B}_{6}^{T} J d \xi=\sum_{i} w_{i} \boldsymbol{B}_{6}^{T}\left(\xi_{i}\right) m_{Y} J, \\
\boldsymbol{F}_{3}^{e} & =\int_{-1}^{1} m_{\varphi_{C Y}^{p}} \boldsymbol{B}_{7}^{T} J d \xi=\sum_{i} w_{i} \boldsymbol{B}_{7}^{T}\left(\xi_{i}\right) m_{\varphi_{C Y}^{p}} J,
\end{aligned}
$$

$\boldsymbol{F}_{i\left(p_{z}\right)}^{e}, \boldsymbol{F}_{i\left(m_{Y}\right)}^{e}, \boldsymbol{F}_{i\left(m_{\varphi_{C Y}}\right)}^{e}$ are the tranverse forces, bending moments, warping moments at the end nodes $i$, respectively,

$$
\begin{aligned}
J & =\frac{L}{2}, \\
\boldsymbol{B}_{1} & =\left[\begin{array}{llllll}
0 & N_{1, x} & 0 & 0 & N_{2, x} & 0
\end{array}\right], \\
\boldsymbol{B}_{2} & =\left[\begin{array}{lllllll}
0 & 0 & N_{1, x} & 0 & 0 & N_{2, x}
\end{array}\right], \\
\boldsymbol{B}_{3} & =\left[\begin{array}{llllll}
N_{1, x} & N_{1} & 0 & N_{2, x} & N_{2} & 0
\end{array}\right], \\
\boldsymbol{B}_{4} & =\left[\begin{array}{lllllll}
-N_{1, x} & -N_{1} & N_{1} & N_{2, x} & -N_{2} & N_{2}
\end{array}\right], \\
\boldsymbol{B}_{5} & =\left[\begin{array}{llllll}
N_{1} & 0 & 0 & N_{2} & 0 & 0
\end{array}\right], \\
\boldsymbol{B}_{6} & =\left[\begin{array}{llllll}
0 & N_{1} & 0 & 0 & N_{2} & 0
\end{array}\right], \\
\boldsymbol{B}_{7} & =\left[\begin{array}{llllll}
0 & 0 & N_{1} & 0 & 0 & N_{2}
\end{array}\right],
\end{aligned}
$$

$w_{i}, \xi_{i}$ are the weights and the integration points of the Gaussian integration technique. In the present study, to avoid the shear locking, we use one-point Gauss quadrature $\left(w_{i}=2, \xi_{i}=0\right)$.

Assembling the element stiffness matrix and load vectors in the system matrix equation given below

$$
\boldsymbol{K} . \boldsymbol{d}=\boldsymbol{F} .
$$

\subsection{Warping function, $\phi_{C Y}^{P}$}

Using Galerkin's method, with test function $\eta \in H_{1}(\Omega)$ and applying the Gauss-Green theorem, the governing Eqs. (6) and (22) are transformed to weak form as

$$
\begin{aligned}
& G\left(\phi_{C Y}^{P}, \eta\right)=0 \\
& \int_{\Omega}\left(\frac{\partial \phi_{C Y}^{P}}{\partial y} \frac{\partial \eta}{\partial y}+\frac{\partial \phi_{C Y}^{P}}{\partial z} \frac{\partial \eta}{\partial z}\right) d \Omega-\int_{\Omega}\left(\frac{A_{Z}^{P}}{I_{Y Y}}\right) \eta d \Omega=0 . \\
& G\left(\tilde{\Phi}_{C Y}^{S}, \eta\right)=0 \\
& \int_{\Omega}\left(\frac{\partial \tilde{\Phi}_{C Y}^{S}}{\partial y} \frac{\partial \eta}{\partial y}+\frac{\partial \tilde{\Phi}_{C Y}^{S}}{\partial z} \frac{\partial \eta}{\partial z}\right) d \Omega-\int_{\Omega} \varphi_{C Y}^{P} \eta d \Omega=0 .
\end{aligned}
$$

The warping function values, $\phi_{C Y}^{P}$ in Eq. (35) and $\tilde{\Phi}_{C Y}^{S}$ in Eq. (36) are approximated by the FEM, which is presented in [37]. Finally, the value $\Phi_{C Y}^{S}$ is calculated from Eq. (12).

\section{Validation examples}

In this section, the accuracy of the proposed FEM for nonuniform bending has been examined. A computer code is developed in the MATLAB R2015a software denoted as RWB based on the formulations described in the previous sections. Thin-walled beams and solid cross-sections under different loading and boundary conditions were analyzed using this code. The obtained results are compared with the available works of the literature.

\subsection{Example 1}

As a first example, a cantilever beam with a box-shaped cross-section shown in Fig. 2 is analyzed and compared with the results obtained by $[8,21]$. The beam is subjected to two load cases separately i) load case 1 with the distributed load $p_{z}=0.1 \mathrm{kN} / \mathrm{cm}$, ii) load case 2 with the concentrated force $P_{z}=4.7 \mathrm{kN}$ applied at the tip of the beam. The length of the
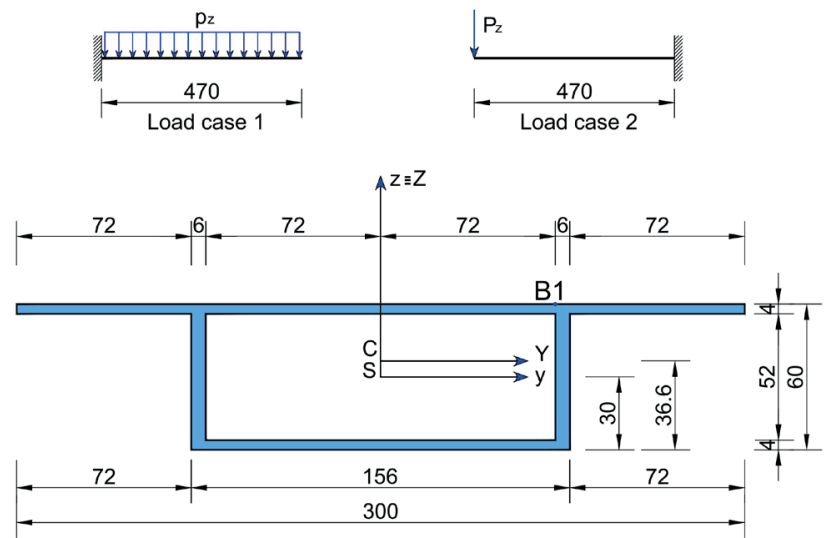

Fig. 2 Cantilever beam with the applied load, and the geometry of the cross-section, units [mm] 
beam is $47 \mathrm{~cm}$. The Young's modulus and the shear modulus are $E=2844.9 \mathrm{MPa}$ and $G=1016.036 \mathrm{MPa}$, respectively. Point $\mathrm{B} 1$ is on the upper plate and has the $\mathrm{y}$ coordinates $72 \mathrm{~mm}$. The first test was analyzed using RWB by employing 15 axial elements and 76 elements in the cross-section. The geometric constants of the cross-section determined from the RWB are as follows $\mathrm{A}=0.00248 \mathrm{~m}^{2}, A_{Z}{ }^{P}=$ $4.0431 \times 10^{-4} \mathrm{~m}^{2}, A_{Z}^{S}=1.3721 \times 10^{-4} \mathrm{~m}^{2}, I_{Y Y}=1.4668 \times 10^{-6} \mathrm{~m}^{4}$, $I_{\varphi_{C Y}^{P} \varphi_{C Y}^{P}}=1.022 \times 10^{-7} \mathrm{~m}^{4}$.

Chang and Zheng [8] experimented with the above problem and used the finite element method to compare the experimental results. Prokić [21] analyzed this problem by finite element method with a postulate warping function. Moreover, Dikaros and Sapountzakis [39] evaluated this test with the model without shear stress correction, which does not give good results as with the model with shear stress correction [27]. In [8, 21], to describe the shear lag effect, the shear lag factor $\lambda$ is defined

$$
\lambda=\frac{\sigma_{x x j}}{\bar{\sigma}_{x x j}},
$$

where $\sigma_{x x j}, \sigma_{x x j}^{-}$are the total normal stress and classic normal stress at the point $j$ of the cross-section, respectively.

In Fig. 3 and Fig. 4, the variation along the axis of the deflection $w(x)$ and the rotation $\theta_{Y}$ predicted by RWB in load cases 1 and 2 are shown and compared with the results from the Timoshenko beam obtained from 1D analysis by SAP2000 ver 21 software [36]. There is a good agreement in the rotation angle between the two methods. The deviation of deflection value at the free end of RWB with SAP2000 in 2 load cases 1 and 2 is $6.427 \%$ and $4.883 \%$, respectively. Fig. 5 depicts the variation along the axis of the warping parameter $\eta_{Y}$ of two load cases.

Fig. 6 and Fig. 7 show the contour plot of the classic normal stress, warping normal stress, and total normal stress $\sigma_{x x}$ in the load case 1 at the positions $x=0,30 \mathrm{~cm}$, respectively. Fig. 8 and Fig. 9 depict the variation of the shear lag factor in one half-length of the upper plate of the cross-section in load case 1 at the positions $x=0,30 \mathrm{~cm}$. Fig. 6 , Fig. 8, the effect of the shear lag phenomenon on the characteristic point B1 is apparent, where $\lambda$ is greater than 1 . It can see from Fig.7, Fig. 9 that RWB can capture the negative shear lag, where $\lambda$ is less than 1 , at the conjunction of flange and web. This phenomenon cannot be ignored, especially in the prestress concrete boxed girder [8].

Fig. 10 and Fig. 11 present the variation along the length of the beam of the shear lag factor at point B1 in load cases 1,2 , respectively. It is observed that the normal stress

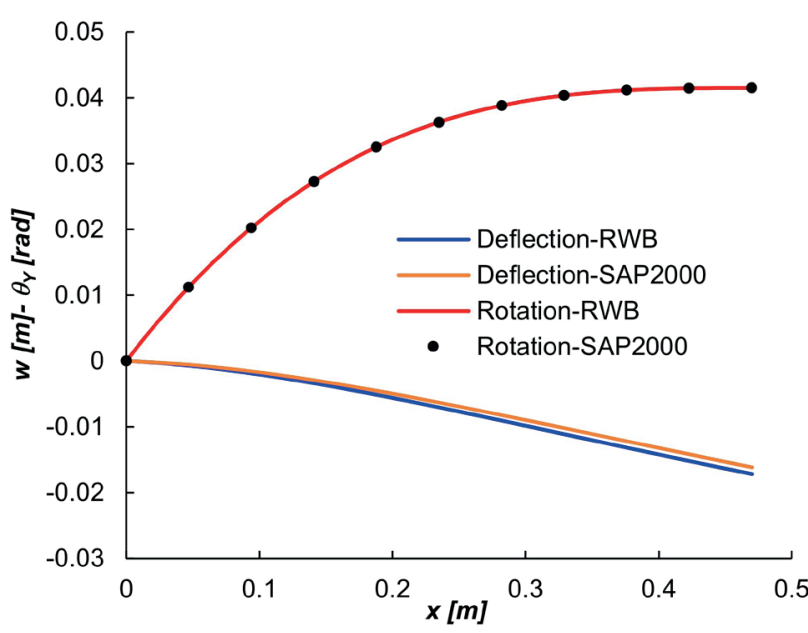

Fig. 3 The variation of deflection $w(x)$, and rotation angle $\theta_{Y}$ along the beam length in load case 1

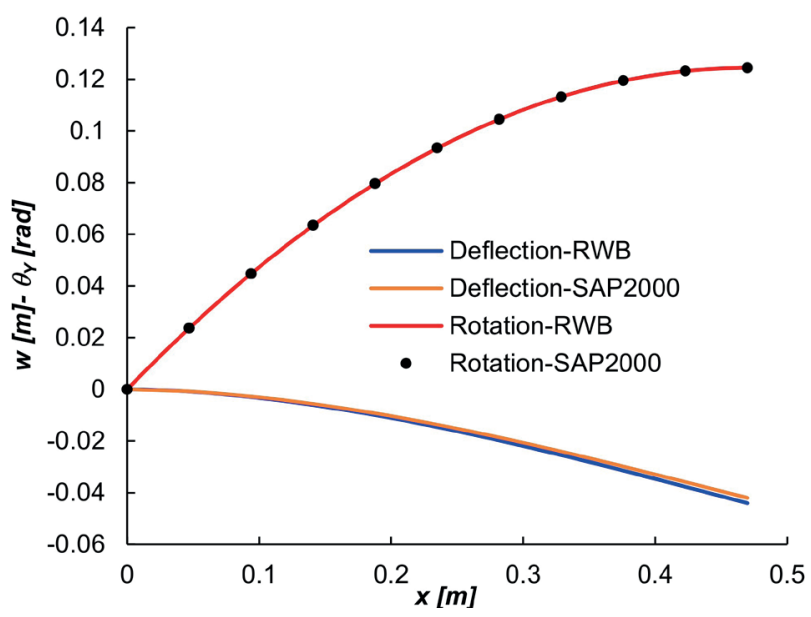

Fig. 4 The variation of deflection $w(x)$, and rotation angle $\theta_{Y}$ along the beam length in load case 2

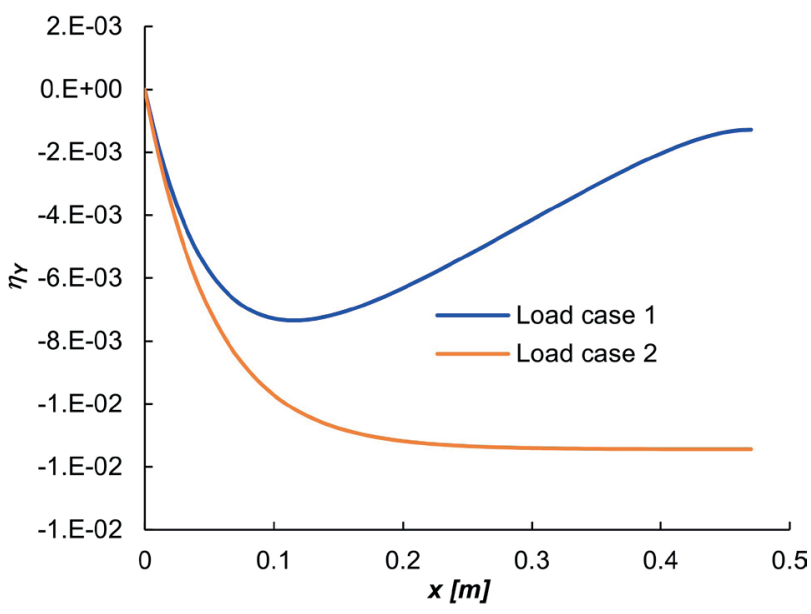

Fig. 5 The variation of bending warping parameter $\eta_{Y}$ along the beam length in load case 1 and load case 2

predicted by RWB is in good agreement with the other methods. It is worth noting that the laws of the variation of the shear lag factor of two load cases 1 and 2 are different. 
It can confirm that the loading condition, which is not mentioned in the standard [2-4], is also one factor affecting shear lag $[33,34]$.

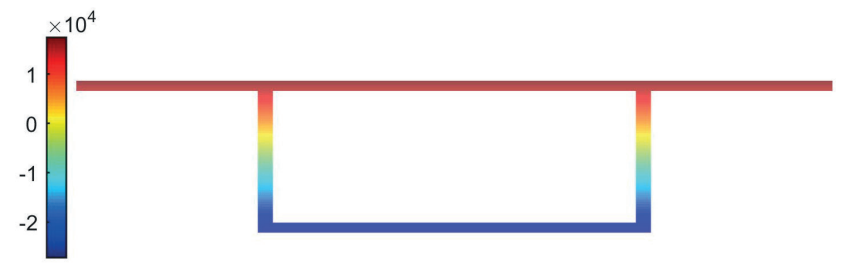

(a)

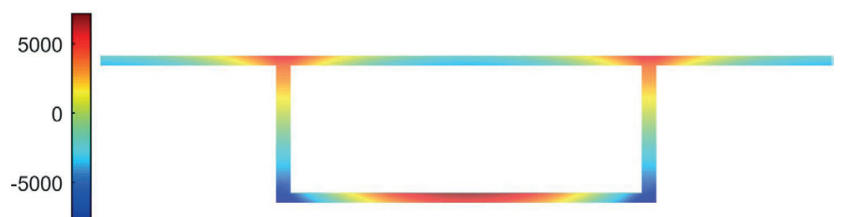

(b)

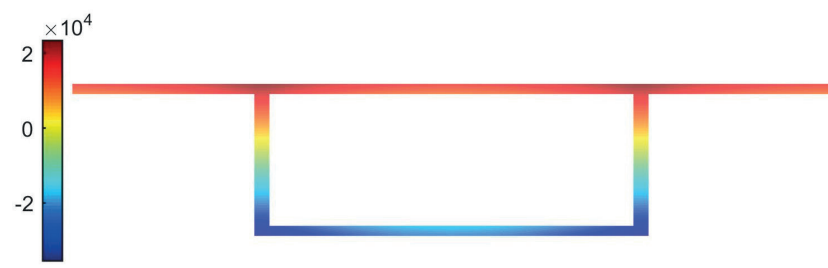

(c)

Fig. 6 The distribution of the classic normal stress, (a) the warping normal stress, (b) and the total normal stress $\sigma_{x x}$, (c) in cross-section at $x=0 \mathrm{~m}$ with load case 1 , units $[\mathrm{kPa}]$

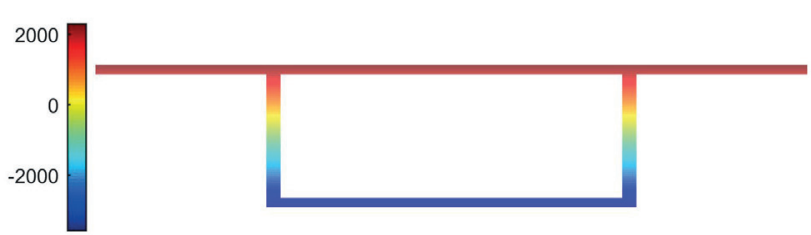

(a)

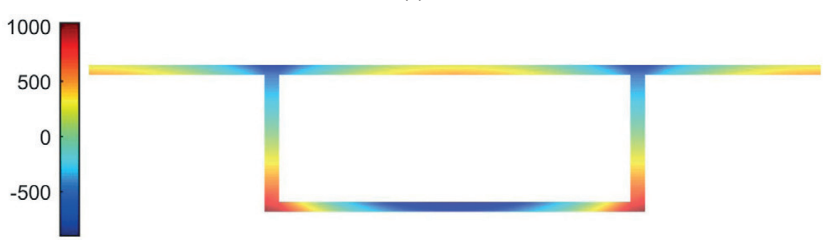

(b)

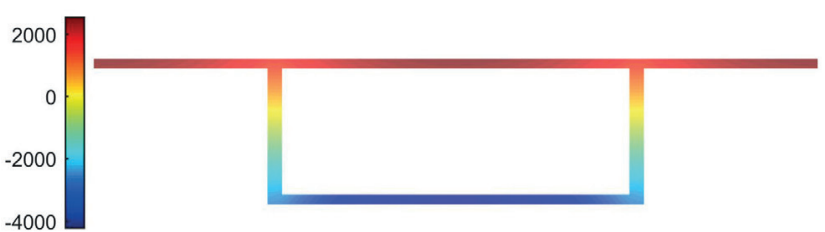

(c)

Fig. 7 The distribution of the classic normal stress, (a) the warping normal stress, (b) and the total normal stress $\sigma_{x x}$, (c) in cross-section at $x=0.3$ m with load case 1 , units $[\mathrm{kPa}]$

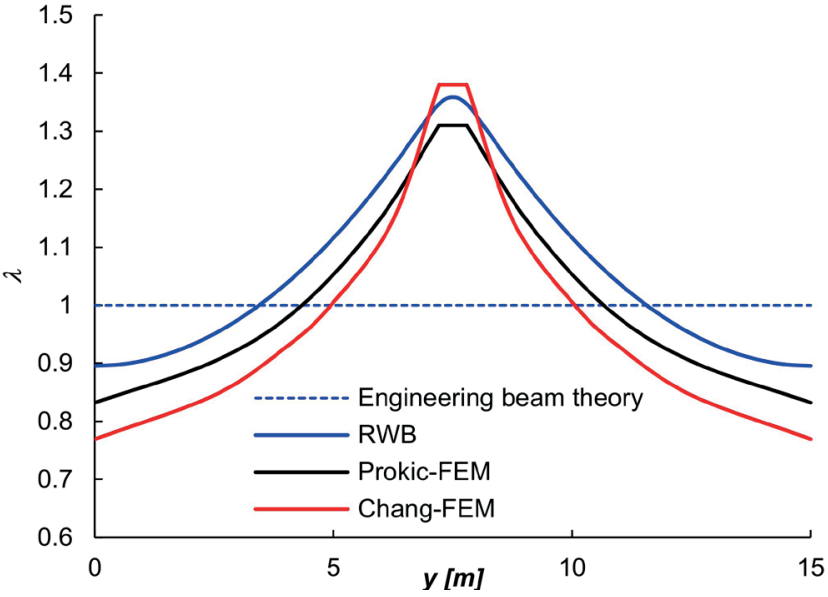

Fig. 8 The variation of the shear lag factor in one a half-length of the upper plate at $x=0$ of load case 1

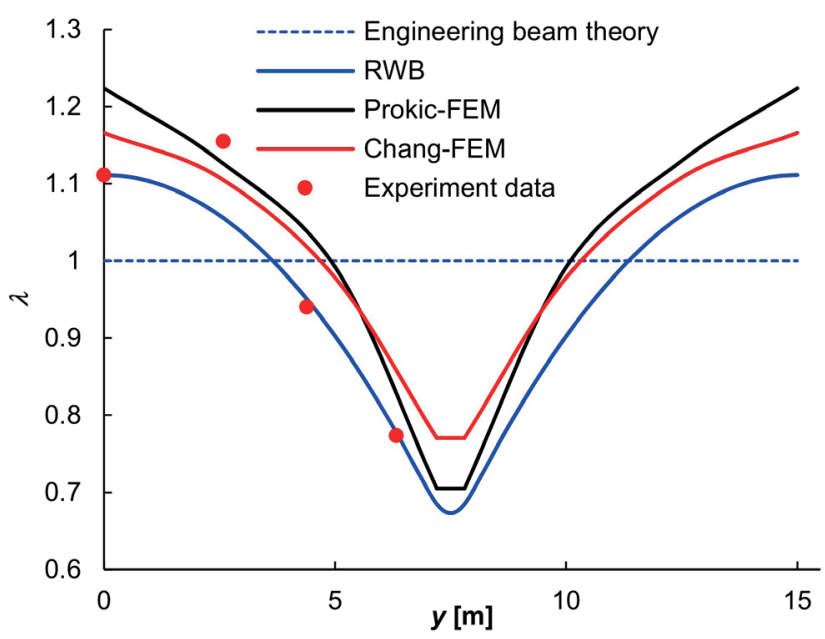

Fig. 9 The variation of the shear lag factor in one a half-length of the upper plate at $x=30 \mathrm{~cm}$ of load case 1

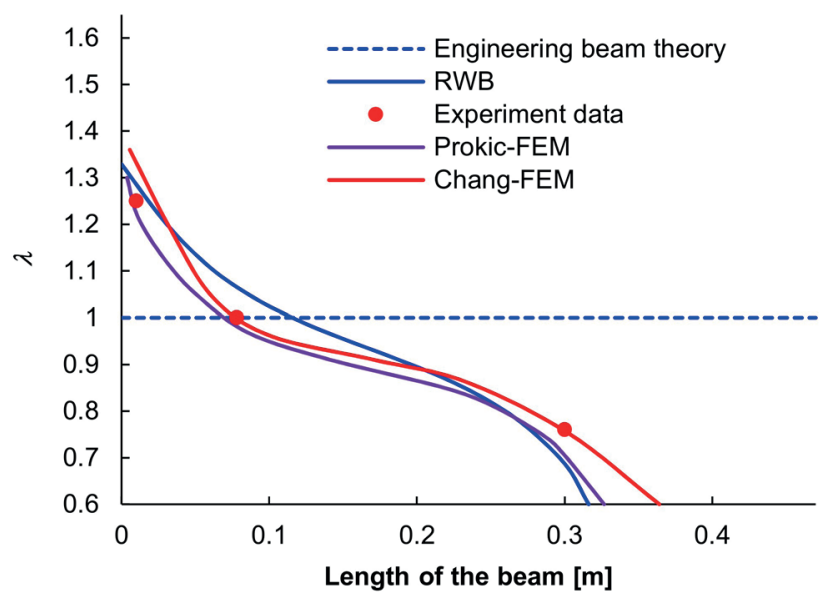

Fig. 10 The variation of the shear lag factor in B1 along the length of the beam in load case 1 


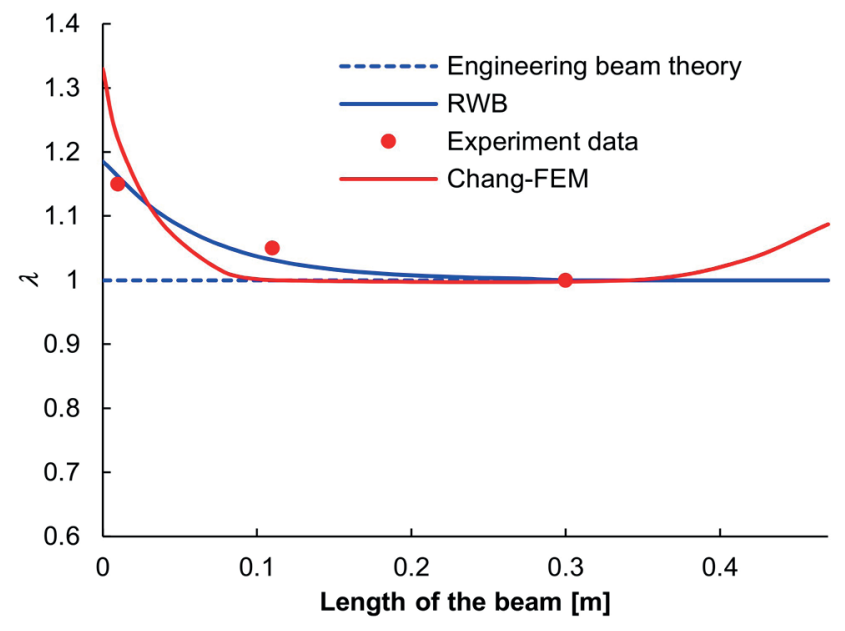

Fig. 11 The variation of the shear lag factor in B1 along the length of the beam in load case 2

\subsection{Example 2}

In the second example a continuous beam with a multi-cell cross-section has been considered. All geometrical characteristics of the beam as well as the boundary and loading conditions are shown in Fig. 12. The Young's modulus and the shear modulus are $E=2.1 \times 10^{5} \mathrm{MPa}, G=1.05 \times 10^{5} \mathrm{MPa}$. As shown in Fig. 12, the concentrated force $P_{z}=10 \mathrm{kN}$ is applied at the positions $x=7.5 \mathrm{~m}$, the uniform distributed $p_{z}=5 \mathrm{kN} / \mathrm{m}$. The second example was analyzed using RWB by employing 400 axial elements and 346 elements in the cross-section. The geometric constants of the cross-section determined from the RWB are as follows $\mathrm{A}=0.1304 \mathrm{~m}^{2}$, $A_{Z}{ }^{P}=0.0481 \mathrm{~m}^{2}, A_{Z}{ }^{S}=0.0055 \mathrm{~m}^{2}, I_{Y Y}=0.004982 \mathrm{~m}^{4}$, $I_{\varphi_{C Y}^{P} \varphi_{C Y}^{P}}^{P}=7.6274 \times 10^{-5} \mathrm{~m}^{4}$.

Sapountzakis and Dikaros [40] analyzed the problem based on BEM with (Model B) and without (Model A) shear stress correction and compared with the result obtained from 3D solid simulation by FEMAP commercial software. It is emphasized that RWB is based on the theory of Model B, which gives more accuracy than Model A.

In Fig. 13, the variation of the deflection $w(x)$ and the rotation $\theta_{Y}$ along the length of the beam predicted by RWB are shown and compared with the results from the Timoshenko beam obtained from SAP2000 ver 21 software [36]. The deviation of deflection value at the positions $x=2.5 \mathrm{~m}, 7.5 \mathrm{~m}$ of RWB with SAP2000 is 4.967\%, 3.577\%, respectively. Fig. 14 shows the variation along the axis of the warping parameter $\eta_{Y}$.

Fig. 15 shows the contour plot of the classic normal stress, warping normal stress, and total normal stress $\sigma_{x x}$ at the fix-end. In Table 1, the normal stress $\sigma_{x x}$ in point B2 at the fixed end predicted by RWB is given and compared

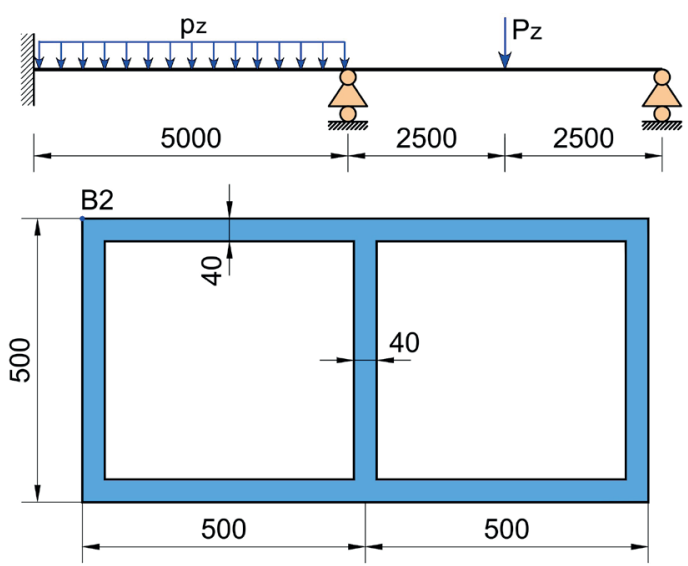

Fig. 12 Continuous beam with the applied load, and the geometry of the cross-section, units [mm]

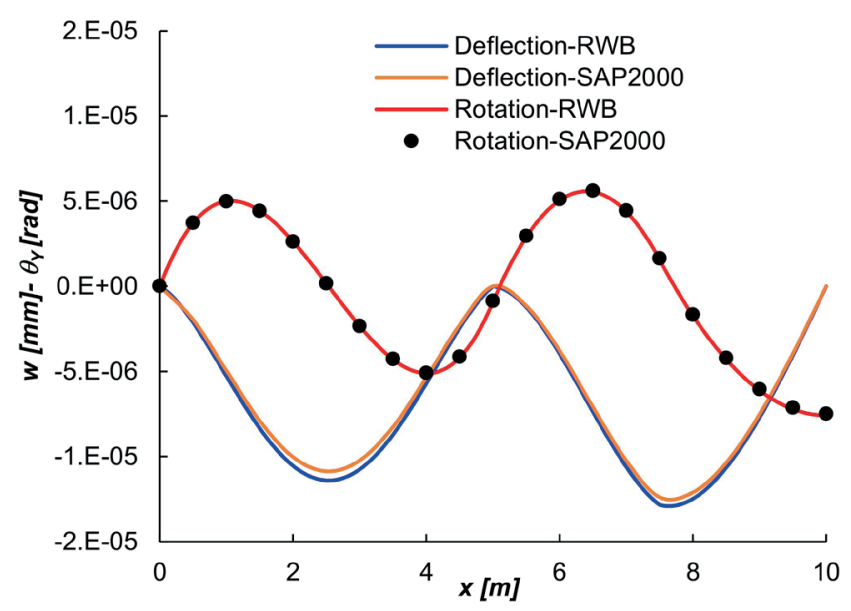

Fig. 13 The variation of deflection $w(x)$, and rotation angle $\theta_{Y}$ along the length of the beam

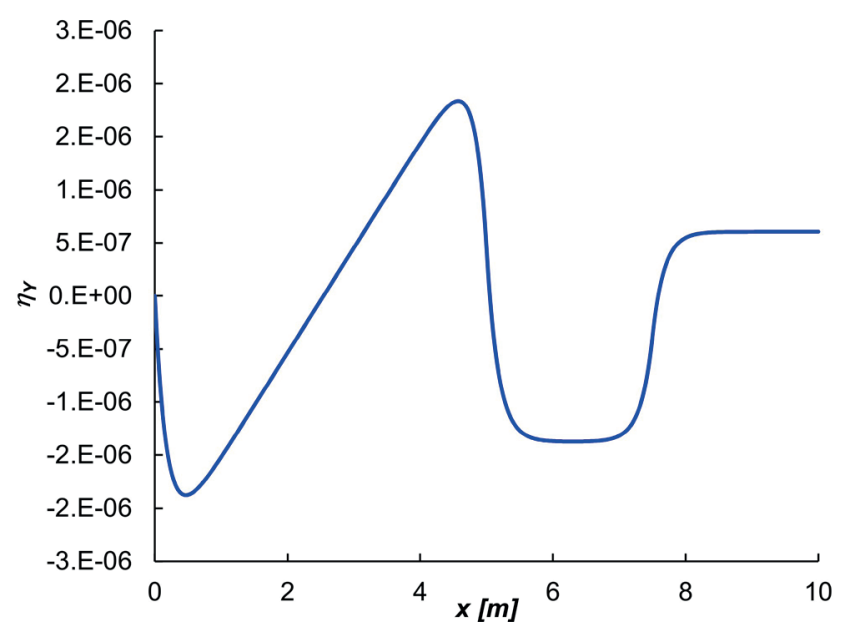

Fig. 14 The variation of bending warping parameter $\eta_{Y}$ along the length of the beam

with the results from [40]. It is observed from Table 1 that the results analyzed by RWB are in good agreement with the results from FEM 3D-Solid [40]. 


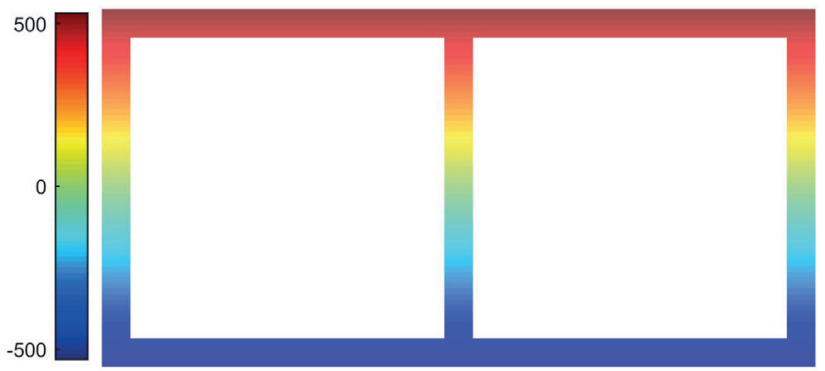

(a)

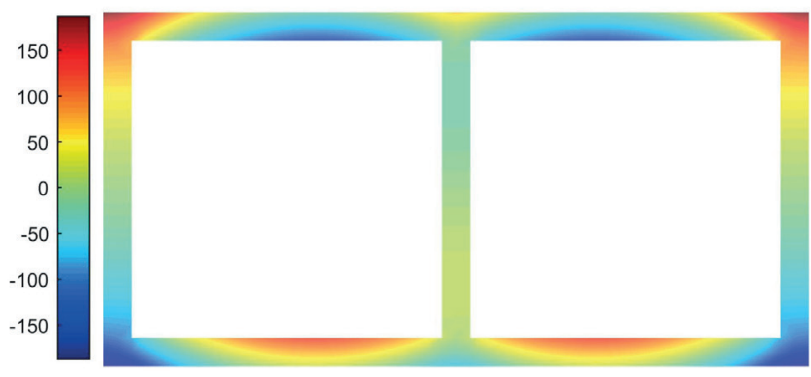

(b)

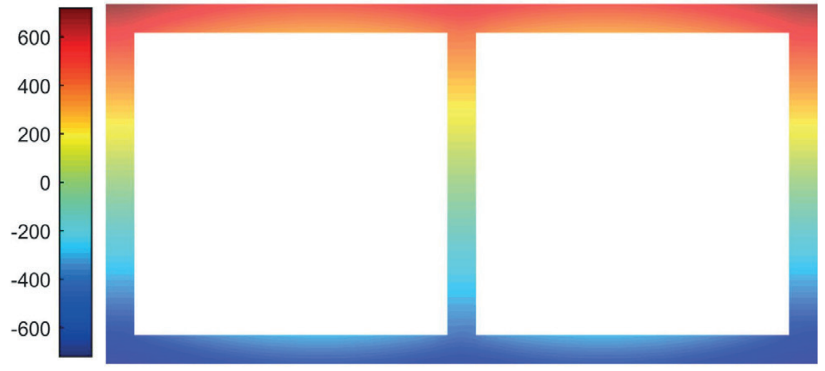

(c)

Fig. 15 The distribution of the classic normal stress, (a) warping normal stress, (b) and the total normal stress $\sigma_{x x}$, (c) in cross-section at the fixed-end, units $[\mathrm{kPa}]$

Table 1 Comparison of the normal stress $\sigma_{x x}$ in the point B2 at the position $x=0 \mathrm{~m}$

\begin{tabular}{lc}
\hline Methods & $\sigma_{x x}[\mathrm{kPa}]$ \\
\hline Engineering beam theory & $5.31405 \times 10^{2}$ \\
RWB & $7.182044 \times 10^{2}$ \\
Model A- Dikaros, I. C. [40] & $1.0417 \times 10^{3}$ \\
Model B- Dikaros, I. C. [40] & $7.0937 \times 10^{2}$ \\
FEM-3D Solid [40] & $7.27 \times 10^{2}$ \\
\hline
\end{tabular}

\subsection{Example 3}

A cantilevered with an I-shaped cross-section depicted in Fig. 16 is analyzed in this section. The length of the beam is $L=6 \mathrm{~m}$ and, it is made of a material with the Modulus of elasticity $E=30 \mathrm{MPa}$ and the Poisson's ratio $v=0.2$. The considered beam is subjected to uniformly distributed force $p_{z}=10 \mathrm{kN} / \mathrm{m}$. The third example was analyzed using RWB by employing 240 axial elements and 76 elements in the cross-section. The geometric constants of the cross-section determined from the RWB are as follows $\mathrm{A}=0.62 \mathrm{~m}^{2}$, $A_{Z}{ }^{P}=0.1159 \mathrm{~m}^{2}, A_{Z}{ }^{S}=0.0337 \mathrm{~m}^{2}, I_{Y Y}=0.0988 \mathrm{~m}^{4}$, $I_{\varphi_{C Y}^{P} \varphi_{C Y}^{P}}=0.0074 \mathrm{~m}^{4}$.

$\mathrm{Ni}$ and Cao [41] used an analytical method to analyze this problem and compared it with the results obtained from ANSYS commercial software by using Solid 45 element. In Fig. 17, the variation along the axis of the deflection $w(x)$ and the rotation $\theta_{Y}$ predicted by RWB is shown and compared with the results from Timoshenko beam obtained from 1D analysis by SAP2000 ver 21 software [36]. There is a good agreement in the rotation angle between two methods. The deviation of deflection value at the free end of RWB with SAP2000 is $7.379 \%$. Fig. 18 depicts the variation along the axis of the warping parameter $\eta_{Y}$.

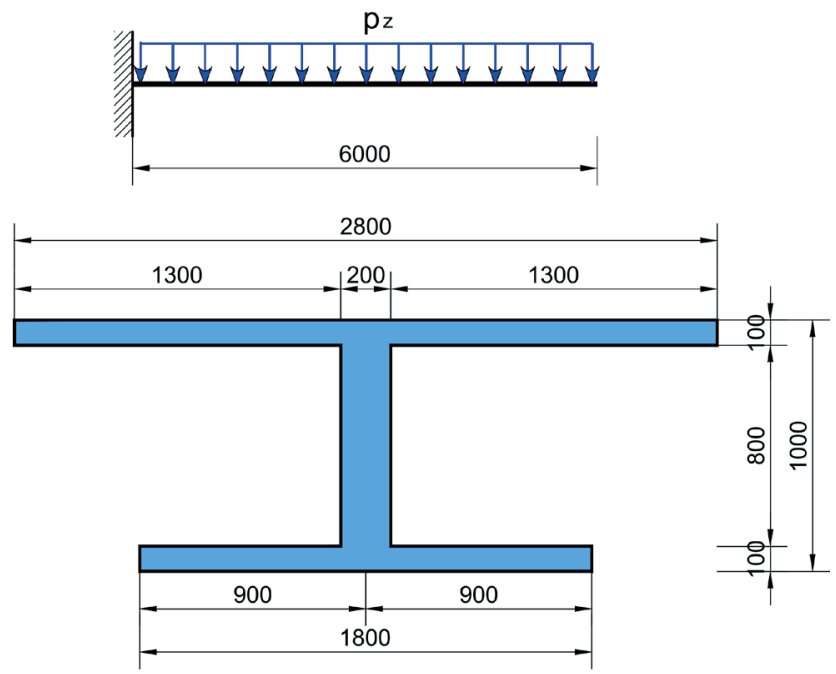

Fig. 16 Cantilever beam with the applied load, and the geometry of the cross-section, units [mm]

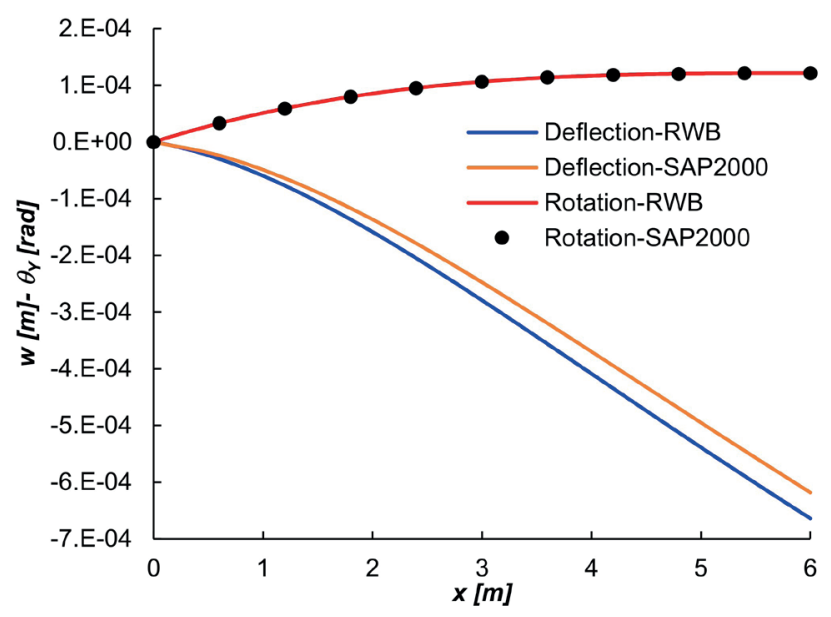

Fig. 17 The variation of deflection $w(x)$, and rotation angle $\theta_{Y}$ along the length of the beam 


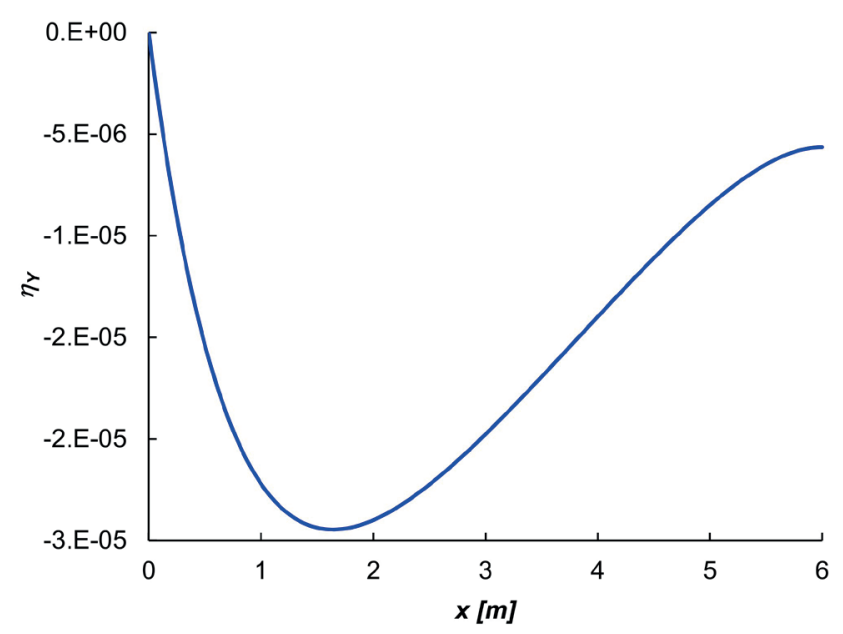

Fig. 18 The variation of bending warping parameter $\eta_{Y}$ along the length of the beam

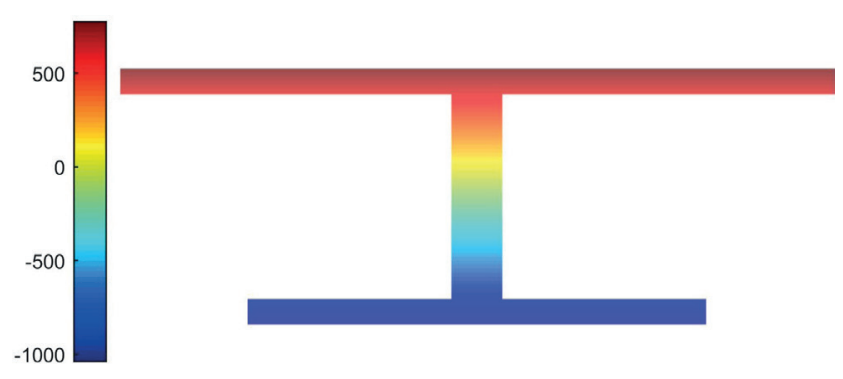

(a)

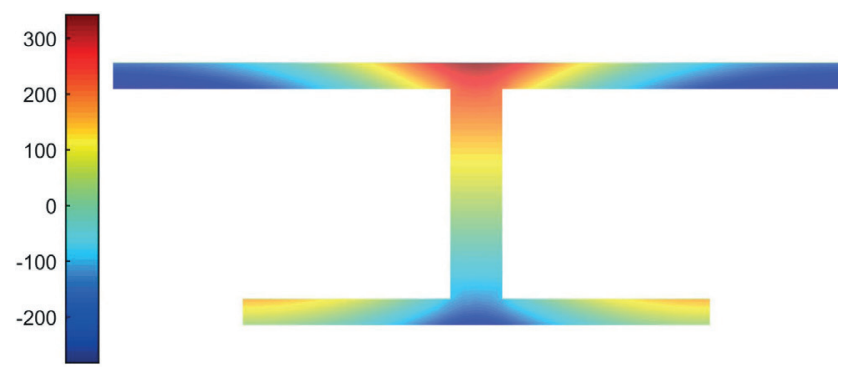

(b)

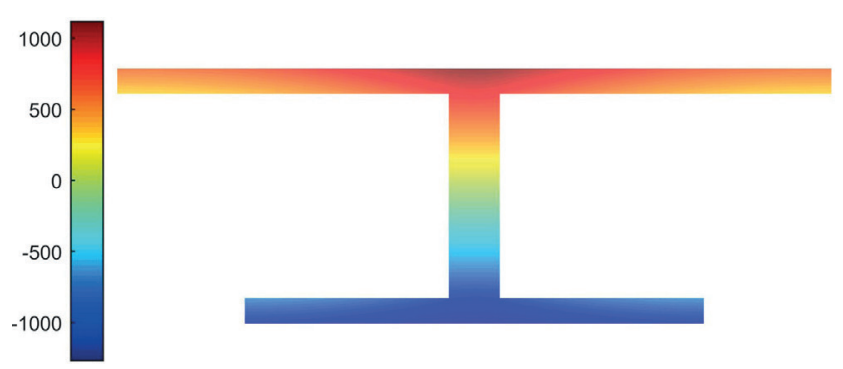

(c)

Fig. 19 The distribution of the classic normal stress, (a) warping normal stress, (b) and the total normal stress $\sigma_{x x}$, (c) in cross-section at the fixed-end, units $[\mathrm{kPa}]$

Fig. 19 shows the contour plot of the classic normal stress, warping normal stress, and total normal stress $\sigma_{x x}$ at the fix-end. Fig. 20 and Fig. 21 present the variation along the width of the normal stress in the upper and lower plate

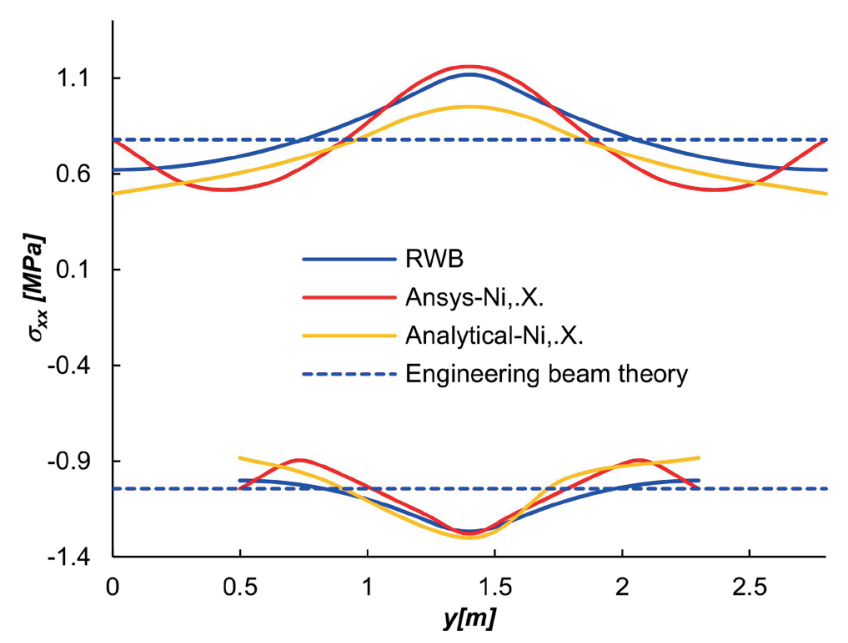

Fig. 20 The variation of normal stress at the upper and lower flange along the width at the fixed end

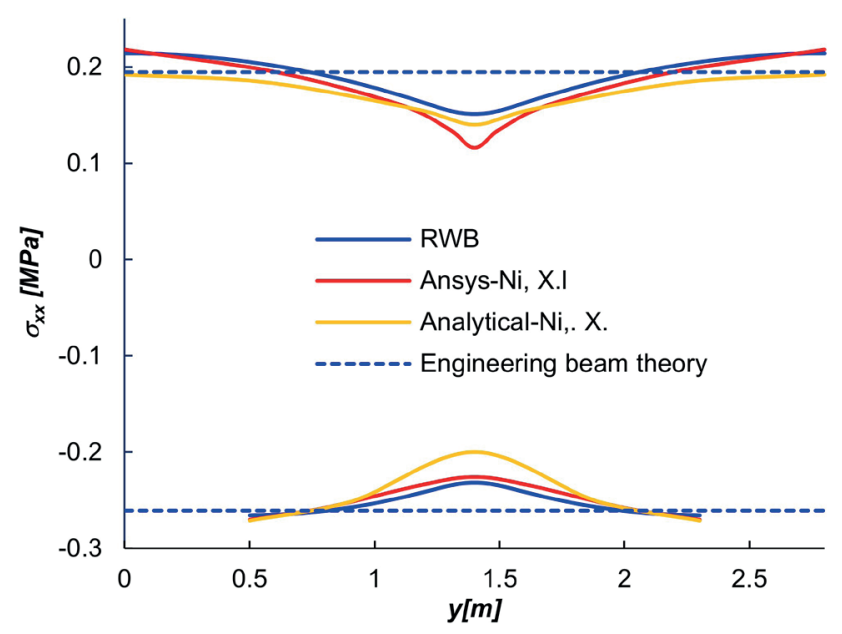

Fig. 21 The variation along the width of the normal stress at the upper and lower flange at $x=3 \mathrm{~m}$

of the cross-section at the positions $x=0,3 \mathrm{~m}$, respectively. It is observed from these figures that the result analyzed by RWB is in good agreement with the results from FEM 3D-Solid.

\section{Conclusions}

In this paper, a finite element method, denoted as RWB, is developed to solve shear lag due to the flexure of the prismatic beam with an arbitrary cross-section and homogeneous isotropic material. Galerkin's method is used to derive the warping function of the corresponding elliptical differential equations. Three independent variables, deflection, rotation angle, and bending warping parameter are obtained by 1D FEM. A set of numerical examples were performed for validating the accuracy of RWB. The results from RWB were compared with the corresponding results in the literature. The main conclusions that can be drawn from this investigation are: 
1. The value of rotation angle calculated by RWB and SAP2000 software is the same. There is a slight difference in the deflection value. The main reason for this difference is the shear correction factor. It is emphasized that the value of the shear correction factor of the RWB takes into account the shape of the cross-section and the Poisson's ratio [37].

2. Boundary conditions, loading type, are the factors affecting the shear lag phenomenon. RWB is capable of capturing the normal stress distribution due to

\section{References}

[1] Křístek, V., Bažant, Z. P. "Shear Lag Effect and Uncertainty in Concrete Box Girder Creep", Journal of Structural Engineering, 113(3), pp. 557-574, 1987. https://doi.org/10.1061/(ASCE)0733-9445(1987)113:3(557)

[2] AASHTO "ASHTO LRFD Bridge Design Specifications", 8th ed., American Association of State Highway and Transportation Officials, Washington, DC, USA, 2017.

[3] CEN "EN 1992-1-1 Eurocode 2: Design Of Concrete Strucutres: General Rules and Rules For Buildings", British Standard Institution, London, UK, 2005.

[4] CEN "Eurocode 3-Design of steel structures-Part 1-5: Plated structural elements", European Committee for Standardization, Brussels, Belgium, 2006.

[5] Reissner, E. "Analysis of shear lag in box beams by the principle of minimum potential energy", Quarterly of Applied Mathematics, 4(3), pp. 268-278, 1946.

https://oi.org/10.1090/qam/17176

[6] Moffatt, K. R., Dowling, P. J. "Shear Lag in Steel Box Girder Bridges", Structural Engineers, 53(10), pp. 439-448, 1975.

[7] Tenchev, R. T. "Shear lag in orthotropic beam flanges and plates with stiffeners", International Journal of Solids and Structures, 33(9), pp. 1317-1334, 1996.

https://doi.org/10.1016/0020-7683(95)00093-3

[8] Chang, S. T., Zheng, F. Z. "Negative Shear Lag in Cantilever Box Girder with Constant Depth", Journal of Structural Engineering, 113(1), pp. 20-35, 1987.

https://doi.org/10.1061/(ASCE)0733-9445(1987)113:1(20)

[9] Luo, Q. Z., Li, Q. S., Tang, J. "Shear lag in box girder bridges", Journal of Bridge Engineering, 7(5), pp. 308-313, 2002. https://doi.org/10.1061/(ASCE)1084-0702(2002)7:5(308)

[10] Luo, Q. Z., Wu, Y. M., Tang, J., Li, Q. S. "Experimental studies on shear lag of box girders", Engineering Structures, 24(4), pp. 469477, 2002.

https://doi.org/10.1016/S0141-0296(01)00113-4

[11] Zhou, S.-J. "Finite Beam Element Considering Shear-Lag Effect in Box Girder", Journal of Engineering Mechanics, 136(9), pp. 11151122, 2010. https://doi.org/10.1061/(ASCE)EM.1943-7889.0000156

[12] Luo, Q. Z., Wu, Y. M., Li, Q. S., Tang, J., Liu, G. D. "A finite segment model for shear lag analysis", Engineering Structures, 26(14), pp. 2113-2124, 2004.

https://doi.org/10.1016/j.engstruct.2004.07.010 shear lag. It is valuable that the results determined by the RWB are in good agreement with the experimental and 3D Simulations.

\section{Acknowledgment}

The works were supported by the Student Grant Competition VSB-TUO. The registration number of the project is SP2021/77 "Nonuniform torsion in prismatic beams with arbitrary cross-sections using FEM".

[13] Chang, S. T. "Shear Lag Effect in Simply Supported Prestressed Concrete Box Girder", Journal of Bridge Engineering, 9(2), pp. 178-184, 2004. https://doi.org/10.1061/(ASCE)1084-0702(2004)9:2(178)

[14] Lee, S. C., Yoo, C. H., Yoon, D. Y. "Analysis of Shear Lag Anomaly in Box Girders", Journal of Structural Engineering, 128(11), pp. 1379-1386, 2002. https://doi.org/10.1061/(ASCE)0733-9445(2002)128:11(1379)

[15] Luo, Q. Z., Tang, J., Li, Q. S. "Shear lag analysis of beam-columns", Engineering Structures, 25(9), pp. 1131-1138, 2003. https://doi.org/10.1016/S0141-0296(03)00061-0

[16] Lin, Z., Zhao, J. "Least-work solutions of flange normal stresses in thin-walled flexural members with high-order polynomial", Engineering Structures, 33(10), pp. 2754-2761, 2011. https://doi.org/10.1016/j.engstruct.2011.05.022

[17] Zhou, S.-J. "Shear Lag Analysis in Prestressed Concrete Box Girders", Journal of Bridge Engineering, 16(4), pp. 500-512, 2011. https://doi.org/10.1061/(ASCE)BE.1943-5592.0000179

[18] Qin, X. X., Liu, H. B., Wang, S. J., Yan, Z. H. "Symplectic Analysis of the Shear Lag Phenomenon in a T-Beam", Journal of Engineering Mechanics, 141(5), Article No. 04014157, 2015. https://doi.org/10.1061/(ASCE)EM.1943-7889.0000882

[19] Zhang, Y.-H. "Improved Finite-Segment Method for Analyzing Shear Lag Effect in Thin-Walled Box Girders", Journal of Structural Engineering, 138(10), pp. 1279-1284, 2012. https://doi.org/10.1061/(ASCE)ST.1943-541X.0000552

[20] Zhang, Y.-H., Lin, L.-X. "Shear lag analysis of thin-walled box girders adopting additional deflection as generalized displacement", Journal of Engineering Mechanics, 140(4), Article No. 4014005, 2014.

https://doi.org/10.1061/(ASCE)EM.1943-7889.0000705

[21] Prokić, A. "New finite element for analysis of shear lag", Computers and Structures, 80(11), pp. 1011-1024, 2002. https://doi.org/10.1016/S0045-7949(02)00036-6

[22] Vlasov, V. Z. "Thin-Walled Elastic Beams", Israel Program for Scientific Translations, Jerusalem, Israel, 1961.

[23] El Fatmi, R. "Non-uniform warping including the effects of torsion and shear forces. Part I: A general beam theory", International Journal of Solids and Structures, 44(18-19), pp. 5912-5929, 2007. https://doi.org/10.1016/j.ijsolstr.2007.02.006 
[24] El Fatmi, R. "Non-uniform warping including the effects of torsion and shear forces. Part II: Analytical and numerical applications", International Journal of Solids and Structures, 44(18-19), pp. 59305952, 2007.

https://doi.org/10.1016/j.ijsolstr.2007.02.005

[25] Le Corvec, V., Filippou, F. C. "Enhanced 3D fiber beam-column element with warping displacements", presented at COMPDYN 2011 3 rd ECCOMAS Thematic Conference on Computational Methods in Structural Dynamics and Earthquake Engineering, Corfu, Greece, May, 25-28, 2011.

[26] Ferradi, M. K., Cespedes, X., Arquier, M. "A higher order beam finite element with warping eigenmodes", Engineering Structures, 46, pp. 748-762, 2013.

https://doi.org/10.1016/j.engstruct.2012.07.038

[27] Dikaros, I. C., Sapountzakis, E. J. "Generalized warping analysis of composite beams of an arbitrary cross section by BEM. I: Theoretical considerations and numerical implementation", Journal of Engineering Mechanics, 140(9), Article No. 4014062, 2014. https://doi.org/10.1061/(ASCE)EM.1943-7889.0000775

[28] Lewiński, T., Czarnecki, S. "On incorporating warping effects due to transverse shear and torsion into the theories of straight elastic bars", Acta Mechanica, 232(1), pp. 247-282, 2021. https://doi.org/10.1007/s00707-020-02849-7

[29] Kim, N.-I., Kim, M.-Y. "Exact dynamic/static stiffness matrices of non-symmetric thin-walled beams considering coupled shear deformation effects", Thin-Walled Structures, 43(5), pp. 701-734, 2005. https://doi.org/10.1016/j.tws.2005.01.004

[30] Librescu, L., Song, O. "Thin-Walled Composite Beams: Theory and Application", Springer, Dordrecht, Netherlands, 2005. https://doi.org/10.1007/1-4020-4203-5

[31] Timoshenko, S. P. "LXVI. On the correction for shear of the differential equation for transverse vibrations of prismatic bars", The London, Edinburgh, and Dublin Philosophical Magazine and Journal of Science, 41(245), pp. 744-746, 1921. https://doi.org/10.1080/14786442108636264

[32] Timoshenko, S. P. "X. On the transverse vibrations of bars of uniform cross-section", The London, Edinburgh, and Dublin Philosophical Magazine and Journal of Science, 43(253), pp. 125-131, 1922. https://doi.org/10.1080/14786442208633855
[33] Sa-nguanmanasak, J., Chaisomphob, T., Yamaguchi, E. "Stress concentration due to shear lag in continuous box girders", Engineering Structures, 29(7), pp. 1414-1421, 2007. https://doi.org/10.1016/j.engstruct.2006.08.010

[34] Yamaguchi, E., Kittaka, N., Maho, B., Sukontasukkul, P. "Shear lag effect on stress concentration in simply-supported stiffened box girder", Journal of Constructional Steel Research, 183, Article No. $106715,2021$. https://doi.org/10.1016/j.jcsr.2021.106715

[35] Paradiso, M., Vaiana, N., Sessa, S., Marmo, F., Rosati, L. "A BEM approach to the evaluation of warping functions in the Saint Venant theory", Engineering Analysis with Boundary Elements, 113, pp. 359-371, 2020. https://doi.org/10.1016/j.enganabound.2020.01.004

[36] Computers and Structures Inc. "CSI Software Products", [online] Available at: https://www.csiamerica.com/products [Accessed: 13 November 2021]

[37] Tran, D.-B., Navrátil, J., Čermák, M. "An efficiency method for assessment of shear stress in prismatic beams with arbitrary cross-sections", Sustainability, 13(2), Article No. 687, 2021. https://doi.org/10.3390/su13020687

[38] Wagner, W., Gruttmann, F. "A displacement method for the analysis of flexural shear stresses in thin-walled isotropic composite beams", Computers and Structures, 80(24), pp. 1843-1851, 2002. https://doi.org/10.1016/S0045-7949(02)00223-7

[39] Dikaros, I. C., Sapountzakis, E. J. "Nonuniform shear warping effect in the analysis of composite beams by BEM", Engineering Structures, 76, pp. 215-234, 2014. https://doi.org/10.1016/j.engstruct.2014.07.009

[40] Sapountzakis, E. J., Dikaros, I. C. "Advanced 3D beam element of arbitrary composite cross section including generalized warping effects", International Journal for Numerical Methods in Engineering, 102(1), pp. 44-78, 2015. https://doi.org/10.1002/nme.4849

[41] Ni, X., Cao, S. "Shear lag analysis of I-shaped structural members", Structural Design of Tall and Special Buildings, 27(10), Article ID e1471, 2018.

https://doi.org/10.1002/tal.1471 